\title{
Microtubule-induced cortical cell polarity
}

\author{
Sarah E. Siegrist and Chris Q. Doe ${ }^{1}$ \\ Institutes of Neuroscience and Molecular Biology, Howard Hughes Medical Institute, University of Oregon, \\ Eugene, Oregon 97403, USA
}

\begin{abstract}
Most cells are polarized. Embryonic and stem cells can use their polarity to generate cell diversity by asymmetric cell division, whereas differentiated cells use their polarity to execute specific functions. For example, fibroblasts form an actin-rich leading edge required for cell migration, neurons form distinctive axonal and dendritic compartments important for directional signaling, and epithelial cells have apical and basolateral cortical domains necessary for maintaining tissue impermeability. It is well established that actin and actin-associated proteins are essential for generating molecular and morphological cell polarity, but only recently has it become accepted that microtubules can induce and/or maintain polarity. One common feature among different cell types is that microtubules can establish the position of cortical polarity, but are not required for cortical polarity per se. In this review, we discuss how different cell types utilize microtubules and microtubule-associated signaling pathways to generate cortical cell polarity, highlight common mechanisms, and discuss open questions for directing future research.
\end{abstract}

Cell polarity is essential for the proper function of many if not all cell types. Polarity can be due to subcellular asymmetric compartmentalization of proteins, mRNAs, and/or organelles, ultimately leading to cell type-specific morphological polarity. Failure to establish or maintain cell polarity can have dire consequences. For example, loss of apical/basal polarity in an epithelial monolayer frequently results in multilayering of cells coupled with uncontrolled cell proliferation (for review, see Bilder 2004).

It has long been recognized that extrinsic cues can induce cell polarity. In this review, we will focus on recent work showing that cell-intrinsic cues from the microtubule cytoskeleton can induce and/or maintain cortical polarity in cells ranging from fission yeast to human fibroblasts. We will not discuss the role of microtubules in plant cell polarity (for review, see Sieberer et al. 2005), nor will we discuss microtubule-dependent cortical events in nonpolarized cells such as specification of the

[Keywords: GEF; dlg; khc-73; microtubule; neuroblast; polarity]

${ }^{1}$ Corresponding author.

E-MAIL cdoe@uoregon.edu; FAX (541) 346-4736.

Article is online at http://www.genesdev.org/cgi/doi/10.1101/gad.1511207. contractile ring position during cytokinesis (for review, see $\mathrm{D}^{\prime}$ Avino et al. 2005).

Microtubules are highly dynamic polar filaments composed of 13 protofilaments, each consisting of a linear array of $\alpha / \beta$-tubulin dimers. Interphase microtubules are organized radially with their slow-growing minus ends anchored at the centrosome (or spindle pole body in yeast) typically near the nucleus and the faster growing plus ends close to the cell cortex. Growing microtubule plus ends are composed of GTP-tubulin, which helps stabilize them (more mature sections of microtubules typically bind microtubule-associated proteins (MAPs), which provide stability). The constant rate of GTP hydrolysis means that microtubules must keep growing to maintain their "GTP-cap," however, and thus stalled microtubules rapidly lose their GTP-tubulin cap and are susceptible to collapse. The cycles of microtubule growth and collapse are termed "dynamic instability." An ever-increasing number of proteins have been identified that localize exclusively to the plus ends of microtubules. A short list of microtubule plus end-binding proteins (also known as +TIPs for microtubule plus endtracking proteins) includes CLIP-170 (cytoplasmic linker protein), APC (adenomatous polyposis coli), and EB1 (end-binding protein 1), as well as the dynactin subunit p150. Functions of +TIPs include regulation of microtubule plus end dynamics as well as providing microtubule-to-cortex attachment necessary for vesicle delivery, force generation, and signaling for cortical cell polarity. Localization of proteins to microtubule plus ends occurs through one of three ways, including kinesin-mediated plus end transport, direct binding to the microtubule plus end itself, and by "hitchhiking" on other proteins already localized at the plus end. Several recent excellent reviews provide more detail (Carvalho et al. 2003; Galjart and Perez 2003; Vaughan 2004; Akhmanova and Hoogenraad 2005; Wu et al. 2006).

Among the different cell types we discuss, one common role for microtubules in generating polarity appears to be their requirement for delivering positional information necessary to establish the proper site of cortical polarity. Once microtubules and their associated proteins determine the polarity site, a positive feedback loop likely initiates acting between the actin-rich cortex and the microtubule plus ends, to reinforce and maintain this polarity site (Fig. 1). While positive feedback loops may initially provide cells with the ability to sense and 


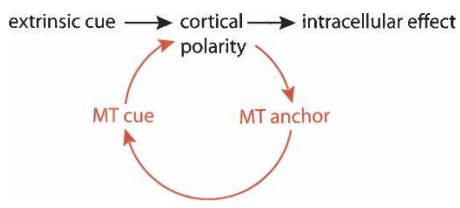

Figure 1. Microtubules can induce and maintain cortical polarity. Extrinsic cues often induce cortical polarity, leading to intracellular effects (black text). In the presence or absence of extrinsic cues, microtubules can induce polarity, and cortical polarity can anchor microtubules, leading to a positive feedback loop that stabilizes the cortical polarity axis (red text).

amplify small asymmetries in their field, these loops may also be important later to buffer and maintain the polarity axis after it is established.

\section{Microtubules induce cortical polarity in fission yeast}

The fission yeast Schizosaccharomyces pombe forms rod-shaped cells due to polarized growth at each tip. Following cell division, the cortex at the oldest tip nucleates actin cables, which promotes polarized vesicle transport resulting in unipolar cell growth. Upon entry into G2, a second cortical polarity site is established at the new end of the cell (a process called "new end takeoff" or NETO), which also nucleates actin cables and initiates tip growth (Mitchison and Nurse 1985). An important question is how a second cortical polarity site is established at the new end, in the presence of the preexisting cortical polarity axis at the old end of the cell. Drug studies and mutants show that microtubules play an essential role in the position of NETO: In the absence of microtubules, cells often form bent or branched shapes due to incorrect positioning of the second polarity axis (Fig. 2A; Umesono et al. 1983; Sawin and Snaith 2004). These studies show that microtubules are not required for growth per se, but rather for the proper positioning of the cortical polarity growth site.

Microtubules are oriented along the length of the cell with their plus ends extending out toward the cell ends, and live imaging studies show that microtubules are highly dynamic, extending and retracting from the cortical tips with a dwell time of $\sim 1-2$ min (Drummond and Cross 2000). Microtubules induce cortical polarity by transporting a protein complex to the new end of the cell. This complex contains the proteins tea2p (kinesin), tealp (kelch repeats and coiled-coil domains), tiplp (CLIP-170 plus end-binding protein family), and the SH3containing tea4p (for review, see Bretscher 2005). The large tea 1 protein directly interacts with tea $4 p$ and tiplp and indirectly links to tea2p via tiplp (Behrens and Nurse 2002; Busch et al. 2004; Feierbach et al. 2004; Martin et al. 2005; Tatebe et al. 2005). Contact of microtubule plus ends with the cortex results in transfer of tealp/tea4p proteins onto the membrane, where they are anchored by direct binding of tealp with the membraneassociated mod5 protein (Browning et al. 2003; Snaith and Sawin 2003; Feierbach et al. 2004; Snaith et al. 2005).
Cells lacking $\bmod 5 \mathrm{p}$ fail to anchor tea1p at the cortex and cells lacking tealp fail to recruit mod5p from around the cell cortex to the tip (Snaith and Sawin 2003), revealing a positive feedback loop that reinforces the microtubule-cortical polarity linkage (Fig. 2B). Mutation in any of these five genes leads to a delay in NETO and occasional bent/branched cell phenotypes, similar to loss of microtubules. As all of these proteins except mod5p are microtubule-associated, it raises the possibility that they act indirectly by promoting microtubule length or dynamics. At least for tealp, this is not the case. Expression of tealp N-terminal domain in cells lacking endogenous tealp rescues microtubule dynamics but tealp remains delocalized from the cortex and cells are still bent or T-shaped, showing that tealp has polarity functions independent of regulating microtubule dynamics (Behrens and Nurse 2002). Thus, microtubules induce tealp/ tea4p cortical polarity via plus end-to-cortex contact.

What is the function of cortical tealp/tea4p in direct-

A

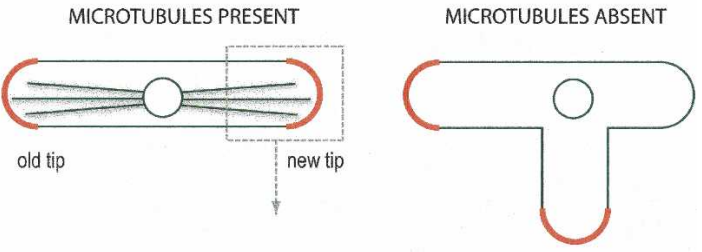

B

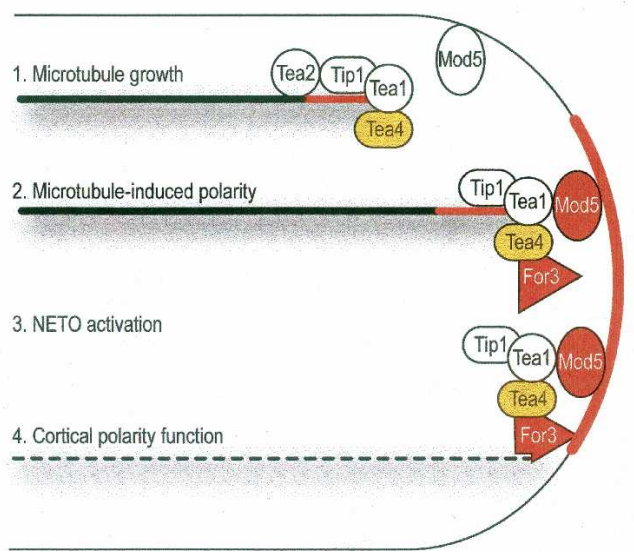

Figure 2. Microtubules induce cortical polarity in S. pombe. (A) Microtubules position the site of cortical polarity. S. pombe shows bipolar growth due to polarized transport of growth components along actin cables to sites of cortical polarity (red). Microtubules are aligned along the growth axis with plus ends contacting and positioning the site of cortical polarity. In the absence of microtubules, cortical polarity is established at incorrect sites, resulting in bent or " $\mathrm{T}$ "-shaped cells. $(B)$ Mechanism of microtubule-induced cortical polarity. In this and subsequent figures, microtubules are represented by black lines, growing microtubule plus ends are shown as a red line, the nucleus is indicated by a circle, the spindle pole body or centrosome is shown by a black dot, the microtubule-associated cortical polarity inducer is represented by orange shapes, microfilaments are marked by a dotted line, and the asymmetrically localized cortical polarity proteins are represented by red shapes. See the text for details. 
ing polarized growth? In $S$. pombe, actin cables orient with their fast-growing plus end toward the cell ends during interphase, and serve as tracks for vesicle delivery and membrane expansion (Marks et al. 1986). Tea4p directly interacts with the formin for $3 p$ that nucleates actin cable assembly together with the actin-binding protein bud6p (Feierbach and Chang 2001; Martin et al. 2005); all three proteins can be found in a single highmolecular-weight protein complex (Glynn et al. 2001; Feierbach et al. 2004). Overexpression of tea4p induces excess actin cable formation, which can be suppressed by removing for3p (Martin et al. 2005). Overexpression of either tealp or for $3 p$ itself does not show a similar phenotype, suggesting that tea4p is a potent formin activator. However tea4p can be functionally replaced by a tea1:for3 fusion protein, suggesting that tea $4 p$ may activate for $3 p$ by localizing it near tealp-associated formin activators such as the small $\mathrm{G}$ protein Rho (Martin et al. 2005). In addition, tealp and for $3 p$ coimmunoprecipitate only in the presence of tea $4 p$ providing further evidence that tea $4 \mathrm{p}$ acts as a bridge between the polarity factor tealp and the growth inducer for3p (Martin et al. 2005). Interestingly, this fusion protein can induce NETO prior to G2 (Martin et al. 2005), as can treatments that expand the actin monomer pool (Rupes et al. 1999), suggesting that Tea $4 \mathrm{p}$ is required to ensure proper temporal activation of for $3 p$-induced actin cable nucleation and timing of NETO. Taken together, these results suggest that microtubules deliver tealp/tea4p to the new end cortex, where tea $4 p$ activates for $3 p /$ bud $6 p$ to locally promote actin cable assembly and cell growth.

Although $S$. pombe remains the best characterized system for studying microtubule-induced cortical polarity, several important questions remain. First, what activates NETO upon entry into G2? Work cited above suggest that G2 events intersect with activation of for3p or actin cable nucleation, but the mechanism is unknown. Second, what is the role of dynamic microtubule-cortex contacts versus stable microtubule "tracks"? Perhaps microtubule collapse is required for release of tiplp/ tealp/tea4 proteins from microtubule plus ends, or perhaps microtubule dynamic instability allows a larger number of productive microtubule-cortex contact events. Third, do microtubules deliver other for $3 p$ activators in addition to tea4p? In other systems Rho-type GTPases activate formins and in S. pombe Rho-type GTPase as well as their activating guanine exchange factors (GEFs) localize to cell tips and are required for bipolar growth (for review, see Garcia et al. 2006b). It would be interesting to test whether microtubules deliver Rho GEFs such as Rgflp to the cell tip during polarized growth (Garcia et al. 2006a).

\section{Microtubules induce cortical Rac1 activation and lamellepodium formation during cell migration}

Here we focus on the polarized migration of fibroblasts, for which the most detailed information about microtubule-induced cortical polarity is known. Excellent reviews of leukocyte chemotaxis and astrocyte migration provide coverage of these closely related areas, where microtubules also regulate aspects of cell polarity (Affolter and Weijer 2005; Etienne-Manneville 2006).

Migrating cells have a stereotypical polarized morphology that predicts their direction of migration. They have a leading edge rich in microfilaments and a trailing membrane domain that must dissolve actin stress fibers and integrin-mediated attachments to the substrate (for review, see Wittmann and Waterman-Storer 2001; Watanabe et al. 2005). During cell migration the microtubule cytoskeleton is polarized: Minus ends are concentrated at the centrosome in the middle of the cell, and plus ends contact the actin-rich leading edge as well as targeting focal adhesions in the rear of the cell (for review, see Small and Kaverina 2003). The first evidence that microtubules were required for directional cell migration, and thus candidates for regulating cortical polarity, came from treatment of fibroblasts with microtubule-depolymerizing drugs, which resulted in reduced, unpolarized membrane ruffling and lack of directional migration (Vasiliev et al. 1970; Goldman 1971; Bershadsky et al. 1991; Grigoriev et al. 1999). Thus, microtubules are essential for proper positioning of the leading edge, but not for migration per se (Fig. 3A).

How do microtubules induce leading-edge cortical polarity (i.e., local actin polymerization)? It is not solely by acting as tracks to deliver cellular components to the leading edge. Low concentrations of nocodazole or Taxol can block cell migration by inhibiting microtubule dynamic instability (such as growth, shortening) without affecting microtubule polarity or abundance (Liao et al. 1995; Mikhailov and Gundersen 1998). In addition, adding Taxol to nocodazole-treated cells can induce the formation of short stable growing microtubules and transient activation of polarized protrusive activity (WatermanStorer et al. 1999). These results suggest that microtubules promote cell polarity by repeated cortical "touches" rather than by forming "tracks" for polarized transport.

How do microtubule plus ends alter cortical polarity? All signs point toward the local activation of the small GTPase Rac1, which is known to stimulate the formation of microfilaments and lamellipodial growth (Ridley et al. 1992; Waterman-Storer et al. 1999; for review, see Hall 2005). Small G proteins like Racl can be activated by GEFs that stimulate exchange of GDP for GTP, and inhibited by GTPase-activating proteins (GAPs) that simulate the intrinsic GTPase activity of the $G$ protein leading to a GDP-bound protein (for review, see Rossman et al. 2005). Increased levels of Racl • GTP correlate with increased rates of microtubule polymerization after nocodazole washout, and Racl • GTP levels are elevated following addition of Taxol to nocodazole-treated cells, which promotes transient microtubule growth (Waterman-Storer et al. 1999).

How do microtubules induce Racl activation? Recent work has shown that microtubules can stimulate cortical Rac1 activity and cell migration through IQGAP1. Despite its name, IQGAP1 is not a GAP that inhibits G protein activity, but rather a large protein that stabilizes and increases $\mathrm{Rac1} \bullet \mathrm{GTP} / \mathrm{Cdc} 42 \bullet \mathrm{GTP}$ levels as well as 
A

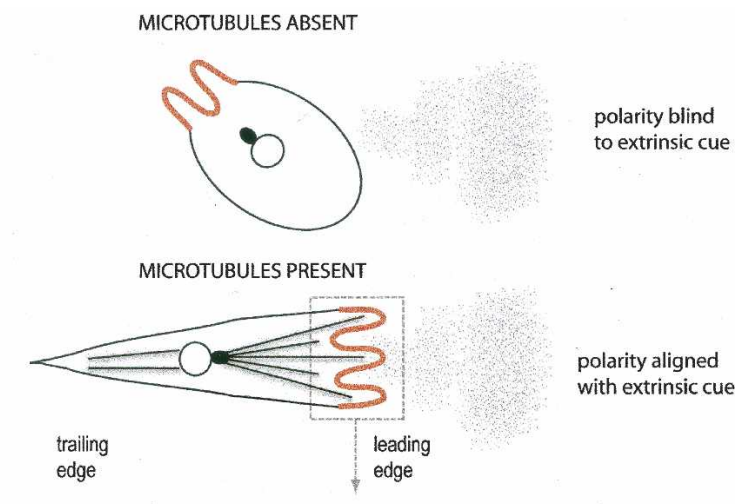

B

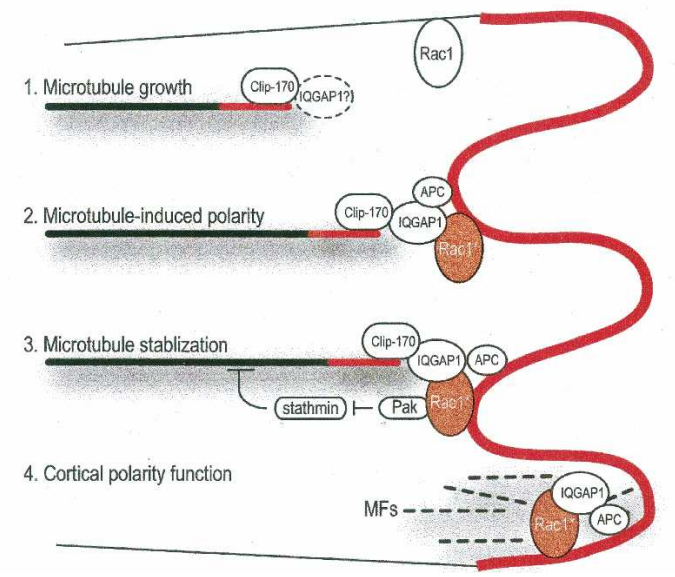

Figure 3. Microtubules determine the site of leading edge cortical polarity during fibroblast migration. (A) Microtubules position the site of cortical polarity. Fibroblast microtubule plus ends contact the leading edge cortex (red) as well as target trailing edge focal adhesions; fibroblasts lacking microtubules can polarize at random cortical sites (red) but do not show directional migration. (B) Mechanism of microtubule-induced cortical polarity. IQGAP1 can induce cortical Rac1 activation $\left(\right.$ Racl $\bullet$ GTP, $\left.\operatorname{Rac}^{\star}{ }^{\star}\right)$. It might be delivered by microtubule plus ends (dotted-outlined IQGAP1), or it might be activated at the cortex by CLIP-170 at growing microtubule plus ends. See the text for details.

cross-links microfilaments (for review, see Briggs and Sacks 2003). Dominant-negative IQGAP1, lacking the Rac1-binding site, lowers Rac1 • GTP levels and decreases cell migration rates (Mataraza et al. 2003). Small interfering RNA (siRNA) knockdown of IQGAP1 depletes actin from the leading edge, reduces lamellipodia, and decreases the rate of migration (Mataraza et al. 2003; Watanabe et al. 2004). In contrast, overexpression of IQGAP1 increases the rate of cell migration in a Rac1dependent manner (Fukata et al. 2002; Mataraza et al. 2003). Thus, IQGAP1 stimulates Racl to induce polarized cell migration-but how? IQGAP1 directly interacts with the microtubule plus end protein CLIP-170, and CLIP-170 is known to "comet" into the leading edge and pause at the cortex (Fukata et al. 2002; Watanabe et al. 2004). IQGAP1 has not been detected at microtubule plus ends, but it is colocalized with Racl at the leading edge cortex, and this cortical localization requires both microtubules and cortical APC (Fukata et al. 2002; Watanabe et al. 2004). One simple model is that small amounts of IQGAP1 are transported by plus end-associated CLIP-170 to the leading edge cortex, where IQGAP1 activates Rac1 (Fig. 3B); alternatively, microtubules/ CLIP-170 could stabilize or activate cortical IQGAP1. Interestingly, activated Racl promotes microtubule/ CLIP-170/IQGAP1 complex formation in vitro, and a longer microtubule-cortex dwell time in vivo (Fukata et al. 2002; Watanabe et al. 2004). This is consistent with a positive feedback loop in which cortical IQGAP1 stimulates Rac1, and Rac1 then promotes microtubule/CLIP170-dependent stabilization of cortical IQGAP1.

In addition to IQGAP1-dependent Rac1 activation, microtubules may be able to stimulate cortical Racl via local delivery of GEFs to the leading edge. Here we will discuss GEF-H1, Trio, and ASEF. GEF-H1 can activate both Rac1 and Rho but not Cdc42 (Ren et al. 1998; Gao et al. 2001; Krendel et al. 2002; Zenke et al. 2004; Callow et al. 2005). When associated with the p21-activated kinase PAK4, GEF-H1 promotes Rac1 activation and lamellipodium formation; in the absence of PAK4 or microtubules, GEF-H1 activates Rho and promotes stress fiber formation (Ren et al. 1998; Gao et al. 2001; Krendel et al. 2002; Callow et al. 2005). GEF-H1 is strikingly microtubule-associated in migrating cells, but it is not enriched at the leading edge cortex (Ren et al. 1998; Glaven et al. 1999; Krendel et al. 2002; Benais-Pont et al. 2003; Callow et al. 2005). Thus, GEF-H1 promotes migration by activating Racl at the leading edge and/or by inhibiting stress fiber formation. Overexpression of the Trio GEF induces lamellipodia formation by activating RhoG, which in turn, activates Racl (Blangy et al. 2000). Trio is also required for cell migration in Caenorhabditis elegans (Honigberg and Kenyon 2000). Trio shows microtubule-dependent localization to the leading edge of migrating fibroblasts, although it has not been detected on microtubules (Blangy et al. 2000). The third GEF, ASEF, is required for cell motility in a colorectal tumor cell line, and ASEF overexpression in an epithelial cell line induces Rac1-dependent polarized membrane ruffles (Kawasaki et al. 2000, 2003). Like Trio, ASEF is detected at the leading edge cortex but not on microtubules, although it can directly interact with the microtubulebinding protein APC (Kawasaki et al. 2000). Thus, at least three GEFs are implicated in microtubule-dependent polarized migration, but there are gaps in each mechanism. Most importantly, it is unknown precisely how dynamic microtubules induce or stabilize Trio and ASEF at the leading edge cortex.

A final twist is that microtubules track along actin cables to "home in" on focal adhesions (Kaverina et al. 1999) and disassemble them by a Rho/Rac-independent pathway that requires Focal adhesion kinase (Fak) and the endocytosis pathway component dynamin (Ezratty et al. 2005). Dynamin is known to bind microtubules (Shpetner and Vallee 1992), raising the interesting possibility that microtubules could deliver dynamin to the focal adhesion, which triggers its removal via endocyto- 
sis. Microtubules could also inhibit focal adhesions by binding and inactivating the RhoGEF activity of GEF-H1 (Krendel et al. 2002; Zenke et al. 2004; Callow et al. 2005). Thus, microtubules may coordinate cell migration in two ways: first, by delivering Racl GEFs to the leading edge to promote actin polymerization and lamellipodia formation, and second, by targeting and destroying focal adhesions in the rear of the cell.

Polarity establishment mechanisms often have positive feedback loops to stabilize the polarity axis, and cell migration is no exception. Microtubules promote Rac1mediated lamellipodium formation, and now recent work shows that cortical Racl can stabilize microtubule plus ends. Racl activation of Pak1 kinase results in phosphorylation and inactivation of stathmin in multiple cell types including migrating cells (Daub et al. 2001; Banerjee et al. 2002; Wittmann et al. 2004); stathmin is a potent microtubule destabilizer (Andersen 2000). Thus, high Rac1 activity promotes microtubule stability. In addition, active Cdc42 at the leading edge leads to the phosphorylation and inactivation of glycogen synthase kinase 3 (GSK-3). GSK-3 phosphorylation requires Par-6 and PKC $\zeta$ kinase activity and leads to recruitment of APC to microtubule plus ends, an important event required for centrosome reorientation (Etienne-Manneville and Hall 2003). In addition, microtubule plus ends can be stabilized by association of the plus end proteins EB1/ APC with the cortical formin Diaphanous (mDia) (Gundersen et al. 2005). EB1/APC/mDia can all be detected at the plus ends of microtubules, and both APC and mDia can be detected at the leading edge cortex (Gundersen et al. 2005). This suggests that migrating cells may use cortical formins to capture and stabilize microtubule plus ends, a nice reversal of the situation in fission yeast where microtubules induce activation of the formin for3p (see above). It will be interesting to determine if for3 $\mathrm{p}$ can stabilize microtubules in yeast, and whether $\mathrm{mDia}$ is activated to promote actin polymerization in the leading edge of migrating cells, which would add two more positive feedback loops linking microtubules and the cell cortex.

\section{Microtubules regulate cortical polarity and actin dynamics in neuronal growth cones}

A specialized form of cell migration is neuronal growth cone guidance. Growth cones are a motile neuronal extension that is similar to the lamellipodia of a migrating fibroblast; growth cones are composed of a peripheral domain rich in actin filaments and a central domain enriched in microtubules (Suter and Forscher 1998). However, recent work has shown that a subset of highly dynamic nonacetylated microtubules constantly probe the peripheral cortical domain, and thus could influence cortical polarity (Schaefer et al. 2002). This is supported by studies showing that exposure of one side of a growth cone to microtubule-stabilizing drugs will stimulate turning toward the drug source, whereas microtubule inhibitors promote turning away (Buck and Zheng 2002). It is important to note that loss of microtubules does not block growth cone extension, but rather leads to a "wandering" growth cone that is blind to environmental guidance cues (Williamson et al. 1996). Thus, microtubules are essential for positioning the site of protrusion within a growth cone, but not for extension per se, similar to their role in migrating cells.

Extrinsic guidance cues could promote microtubuleinduced cortical polarity in a turning growth cone either by changing the actin-rich cortex to foster microtubulecortex anchoring or by directly affecting microtubule dynamics; if there is a positive feedback loop between microtubules and the cortex (Fig. 1), then both mechanisms would lead to microtubule-dependent growth cone guidance. The former model is supported by a number of recent studies. First, actin cables are required for protrusion of dynamic microtubules into the peripheral growth cone (Kabir et al. 2001; Schaefer et al. 2002; Zhou et al. 2002), suggesting that the actin cortex can affect the timing and number of microtubule-cortex interactions. However, there is also evidence for direct regulation of microtubules by extrinsic guidance cue signaling pathways. Growth cones exposed to the attractive cue nerve growth factor (NGF) show increased levels of dephosphorylated APC (Zhou et al. 2004), which directly stimulate microtubule plus end stability (Zumbrunn et al. 2001). This could result in an increase in microtubulecortex interactions on the growing side of the growth cone. Additional evidence for direct regulation of microtubules by guidance cues comes from analysis of the repulsive Slit/Robo pathway. Genetic data in Drosophila show that growth cone repulsion from the midline source of Slit is impaired in mutants for the receptor Roundabout (Robo), the Ableson (Abl) tyrosine kinase, and the microtubule plus end-binding and stabilizing Orbit/CLASP protein (Lee et al. 2004). The authors propose a model in which Slit stabilizes microtubules (i.e., reducing dynamic microtubule-cortex interactions), resulting in growth cone migration away from the cue. In support of their model, CLASP can be detected in Drosophila growth cones in vivo, decorates pioneer microtubule plus ends in cultured Xenopus growth cones, and overexpression of CLASP in Xenopus neurons results in looping and decreased growth of microtubules (Lee et al. 2004). It remains unclear why stabilized microtubules promote growth cone turning toward NGF (Zumbrunn et al. 2001), whereas they lead to growth cone repulsion in response to Slit (Lee et al. 2004). Perhaps an intermediate level of stabilized microtubules are essential for growth cone turning, and too little or too much is deleterious. Resolving this question will require high temporal resolution imaging of microtubule plus ends during growth cone turning in each system.

Although evidence that microtubules can alter growth cone migration is accumulating (for review, see Rodriguez et al. 2003), little is known about how microtubule plus ends induce filopodia or lamellipodial extension. The most attractive models are that microtubule plus end-binding proteins deliver Rac activators (e.g., IQGAP1, ASEF, Trio) to one side of the growth cone resulting in actin polymerization and directed migration, 
as they do in fibroblasts. In fact, several microtubule plus end-binding proteins are localized to growth cone microtubules, such as CLIP-170, EB3 (Stepanova et al. 2003), and APC (Zhou et al. 2004; Shimomura et al. 2005). Testing these +TIP proteins for role in microtubule-regulated growth cone guidance will reveal whether growth cones and migrating fibroblasts share fundamental mechanisms for directional migration.

\section{Microtubules induce apical cortical polarity in Drosophila epithelia}

Drosophila embryos develop from a synctial embryo with 5000 nuclei. These nuclei migrate to the cortex where membrane invaginations around each nucleus leads to the formation of a surface cell layer that develops apical/basal cortical polarity; this process is termed cellularization. Immediately after cellularization, ventral cells undergo an apical constriction that results in the invagination of the future mesoderm (gastrulation). Similar apical constrictions are observed in gastrulating cells in many embryos, as well as during placode invagination. Recent work has provided insight into how microtubules regulate cortical polarity during each of these processes.

How do microtubules regulate apical cortical constriction in gastrulating cells? The physical constriction of these cells requires activation of the conserved Rhol/ Rho kinase/myosin light chain kinase/myosin II pathway at the apical cortex (Barrett et al. 1997; Hacker and Perrimon 1998). Insight into how microtubules activate Rhol at the apical cortex have come from pioneering biochemical experiments that identified a Rho-activating protein, RhoGEF2, as a binding partner of the microtubule plus end-binding protein EB1, which is required for apical constriction of gastrulating cells (Rogers et al. 2004). Further experiments in the nonepithelial S2 cell line revealed that (1) RhoGEF2 requires EB1 for its association with growing microtubule plus ends; $(2)$ the concertina $\mathrm{G} \alpha \cdot \mathrm{GTP}$ heterotrimeric $\mathrm{G}$ protein subunit triggers movement of RhoGEF2 from the microtubule plus end to the cortex; and (3) RhoGEF2 acts via Rho1 and Rho kinase to activate myosin II-dependent cortical contractions (Rogers et al. 2004). This has led to a model in which microtubules deliver RhoGEF2 to the apical cortex, where it induces Rhol-dependent myosin II contractility during gastrulation. It is important to note that RhoGEF2 has not yet been observed on microtubule plus ends in gastrulating cells (only S2 cells), and it is possible that it acts by a different mechanism in each cell type. Other questions remain, including how the timing of apical constriction is regulated; one possibility is that the process is initiated by ligand-induced activation of the concertina $\mathrm{G} \alpha$ protein.

Microtubules are also used to induce cadherin cortical polarity in epithelial cells (Fig. 4A). Cadherins are transmembrane proteins that mediate epithelial cell-cell adhesions through calcium-dependent homotypic binding (Takeichi 1991). Several lines of evidence show that dynamic microtubules promote clustering of surface cad-
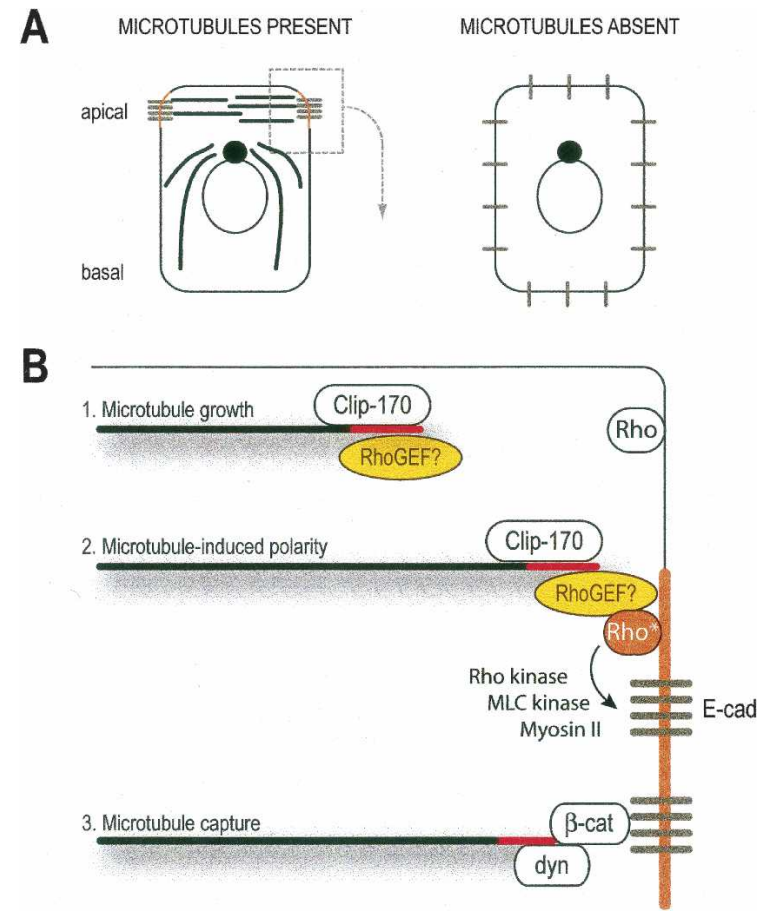

Figure 4. Microtubules induce cadherin clustering in Drosophila epithelia. (A) Microtubules position the site of cortical polarity. Dynamic noncentrosomal microtubules are required to induce cadherin clustering. Gray ticks represent E-cadherin protein. (B) Mechanism of microtubule-induced cortical polarity. The role of the Rho GEF is speculative based on its role in activating cortical Rho (Rho $\bullet$ GTP, Rho*) in the nonepithelial S2 cell line (Rogers et al. 2004). See the text for details.

herin protein at the site of cell-cell contacts. First, the plus ends of highly dynamic, nonacetylated microtubules directly contact cadherin-based cell junctions (Stehbens et al. 2006). Second, low concentrations of nocodazole abolish these dynamic microtubules without grossly affecting microtubule morphology, and result in the disruption of cell-cell junctions, suggesting that dynamic microtubules are required to maintain cell-cell adhesion (Waterman-Storer et al. 2000). While microtubule motors are required to localize cadherin to the cell surface in myoblasts (Mary et al. 2002), localization of cadherin in epithelial cells may occur through a transport-independent mechanism. When dynamic microtubules are disrupted with a dominant-negative CLIP-170 protein, it results in the loss of cadherin clustering and cell adhesion without lowering the overall level of cell surface cadherin (Stehbens et al. 2006). Moreover, photobleaching of cortical cadherin-YFP fluorescence led to rapid recovery in wild-type cells, but delayed recovery in nocodazole-treated cells, consistent with a defect in cadherin clustering (Waterman-Storer et al. 2000). Thus, dynamic microtubule plus ends are required for proper cadherin clustering and cell-cell adhesion.

How do microtubules concentrate cadherin at sites of cell-cell contact? Recent work shows that microtubuleinduced cadherin clustering requires the Rho/Rho ki- 
nase/myosin light chain kinase/myosin II pathway, similar to the pathway of microtubule-induced apical cortical constriction in gastrulating cells (see above). Microtubules are required for recruiting myosin II to sites of cadherin clustering, and pharmacological inhibition of Rho kinase or myosin II activity prevents cadherin clustering and proper cell-cell junctions (Braga et al. 1997; Takaishi et al. 1997; Vaezi et al. 2002; Shewan et al. 2005; Stehbens et al. 2006). It is currently unknown how microtubules promote Rho activation, but it is appealing to consider a pathway in which microtubule plus ends deliver a Rho GEF to the cortex to stimulate Rho activity (Fig. 4B).

Data consistent with a model of microtubule-induced Rho activation exists in several other cell types, but in no case is the entire pathway clearly elucidated. RhoGEF2 or other Rho GEFs are required for Drosophila cellularization, pole cell cytokinesis, epithelial folding in Drosophila (Nikolaidou and Barrett 2004; Padash Barmchi et al. 2005); and activated RhoA is specifically localized to cortical domains involved in pole cell and micromere cytokinesis in sea urchins and Xenopus (Bement et al. 2005; Ma et al. 2006), but whether microtubules deliver Rho GEFs to the cortex remains unknown. In contrast, there is evidence that microtubules induce cortical polarity during Drosophila epithelial planar cell polarity and dorsal closure. Planar cell polarity is established along the proximal/distal axis of an epithelial sheet in many organisms, and in Drosophila it results in the formation of an actin-rich protrusion from the distal side of the cell. Noncentrosomal microtubules are aligned along the proximodistal axis of these cells, with slightly more plus ends toward the distal side of the cell, and are required for clustering the transmembrane Frizzled receptor, E-cadherin, and several other proteins at the distal side of the cell (Shimada et al. 2006). Microtubules are also essential for generating myosin-dependent epithelial cell protrusions during Drosophila dorsal closure (a process similar to epithelial wound healing) (Jankovics and Brunner 2006). The mechanism of microtubule-induced cortical polarity remains unknown for both planar cell polarity and dorsal closure, and more specifically, it has not been tested whether microtubules act via delivery of a Rho GEF to the cortex in either cell type.

\section{Microtubules induce apical cortical polarity in Drosophila neuroblasts}

Asymmetric cell division requires that the dividing cell is polarized and the mitotic spindle is aligned with the polarity axis such that daughter cells are molecularly distinct. Neuroblasts are the stem cell-like progenitors of the Drosophila CNS that undergo asymmetric cell division to generate another proliferative neuroblast and a smaller differentiating daughter cell that generates neurons or glia. Mitotic neuroblasts have striking cortical polarity, with over a dozen proteins targeted to their apical cortex (future neuroblast) and at least six proteins targeted to the opposite basal cortex (future daughter cell). The mitotic spindle aligns with the cortical polar- ity axis, and the neuroblast undergoes asymmetric cell division, with the larger neuroblast inheriting apical proteins and the smaller GMC inheriting basal proteins. Establishment and maintenance of neuroblast cortical polarity requires microfilaments (Broadus and Doe 1997), but until recently there has been no evidence that microtubules are involved. Treatment of wild-type neuroblasts with microtubule inhibitors arrests the cells in mitosis but apical and basal cortical polarity can be established (Knoblich et al. 1995; Spana and Doe 1995; Broadus and Doe 1997). The only early sign that microtubules play a role in neuroblast cortical polarity came from double drug studies, in which microfilament inhibitor treatment resulted in uniform cortical apical protein localization, but microfilament plus microtubule inhibitor treatment resulted in apical proteins delocalizing into the cytoplasm (Broadus and Doe 1997). This suggested that microtubules might play a role in cortical targeting of apical proteins.

The breakthrough in understanding the role of microtubule-induced cortical polarity came from analysis of inscuteable (insc) mutants (Siegrist and Doe 2005). The Insc protein links two evolutionarily conserved protein complexes at the apical cortex of the neuroblast. One is the Par complex, consisting of Par-3 (Bazooka in Drosophila), aPKC, and Par-6; the other is the Pins complex, consisting of Partner of Inscuteable (Pins), the heterotrimeric G protein subunits $\mathrm{G} \alpha \mathrm{i} / \mathrm{G} \alpha \mathrm{O}$, and the tumor suppressor protein Discs large (Dlg). In insc mutants, the Par complex is delocalized into the cytoplasm, but the Pins/ $\mathrm{G} \alpha / \mathrm{Dlg}$ complex still forms crescents (Siegrist and Doe 2005). Importantly, the Pins $/ \mathrm{G} \alpha / \mathrm{Dlg}$ crescents are always over one spindle pole, even when the spindle is aligned perpendicular to the normal apical/basal axis (Fig. 5A).

To determine whether microtubules induce Pins/G $\alpha /$ Dlg cortical polarity, or vice versa, insc mutant neuroblasts were treated with microtubule depolymerizing drugs. Treatment of mitotic insc mutant neuroblasts with either Colcemid (which abolished all detectable microtubules) or nocodazole (which at the concentration used specifically abolished astral microtubules) resulted in delocalization of Pins/G $\alpha / \mathrm{Dlg}$ proteins; a similar result was observed in fizzy insc double mutants, in which neuroblasts have a small barrel-shaped spindle that lacks astral microtubules (Siegrist and Doe 2005). Thus, astral microtubules can induce Pins/G $\alpha / D l g$ cortical polarity in metaphase neuroblasts, suggesting that direct contact between microtubules and cortex is required to generate polarity (Fig. 5A).

How do astral microtubules induce Pins $/ \mathrm{G} \alpha / \mathrm{Dlg}$ cortical polarity? A key component is the kinesin 3 family member Khc73. Drosophila Khc73 is related to the human Gakin/Kif13b kinesin: Both Khc73 and Gakin have a conventional microtubule plus end-directed motor domain, a microtubule plus end-binding CAP-Gly domain, and a central conserved domain that can bind the Cterminal GK domain of human or Drosophila Dlg (Li et al. 1997; Hanada et al. 2000; Asaba et al. 2003; Siegrist and Doe 2005). When Khc73 is depleted by RNA inter- 

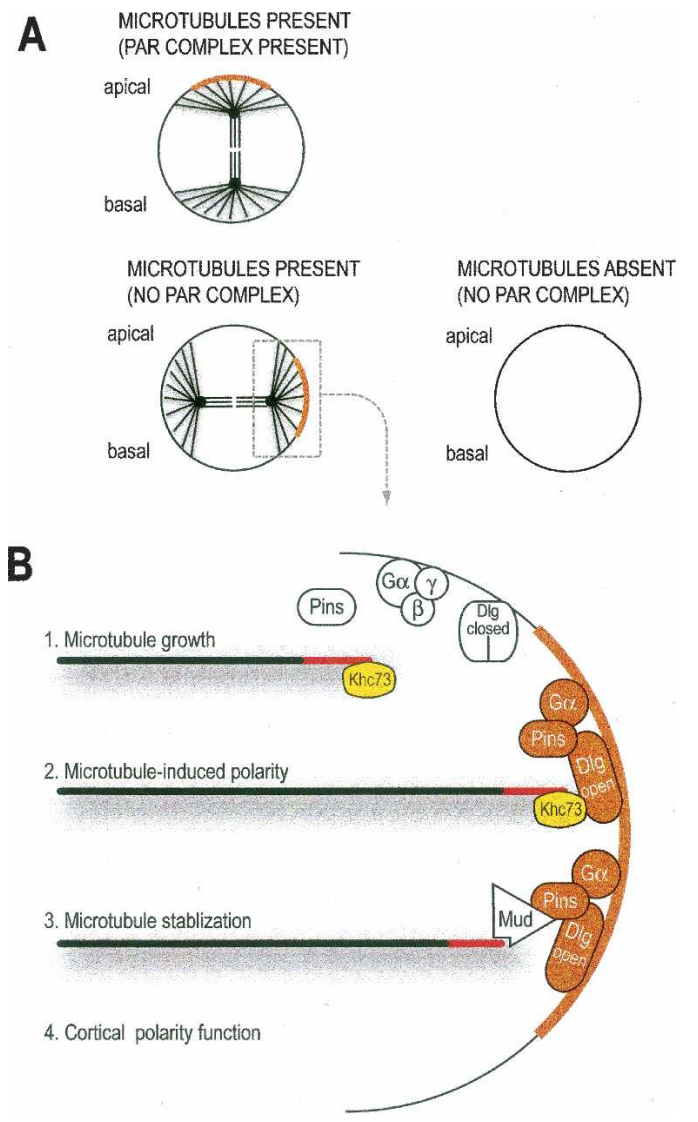

Figure 5. Microtubules induce apical cortical polarity in Drosophila neuroblasts. (A) Microtubules can induce neuroblast cortical polarity. Wild-type neuroblasts have apical Par complex proteins (label, Par-3/Par-6/aPKC), which normally recruit the Pins complex (Dlg/Pins/Gai, red) to the apical cortex. In the absence of the Par complex, astral microtubules are necessary and sufficient to induce Pins complex cortical polarity. $(B)$ Mechanism of microtubule-induced cortical polarity. (Khc73) Kinesin heavy chain 73 ; (Dlg closed) Dlg with intramolecular association of its SH3-GK domains; (Dlg open) Dlg where its SH3 and GK domains are bound to other proteins (e.g., Khc73GK and Pins-SH3). See the text for details.

ference (RNAi) in insc mutant neuroblasts, Pins $/ \mathrm{G} \alpha / \mathrm{Dlg}$ cortical polarity is abolished; similarly, expression of a dominant-negative form of Khc73 (the presumed Dlgbinding domain alone) also abolishes Pins/G $\alpha / \mathrm{Dlg}$ cortical polarity in insc mutant neuroblasts (Siegrist and Doe 2005). It is not fully established how Khc73 induces Pins/G $\alpha / D l g$ cortical polarity. Khc73 could merely promote microtubule growth or stability, although no defects in spindle organization were seen in neuroblasts lacking Khc73. Alternate models are that Khc73 transports Dlg to the cortex, or Khc73 at microtubule plus ends induces clustering (oligomerization) of cortical Dlg protein. The latter model is supported by the observation that Dlg is not detected on microtubules, and that an epitope-tagged Khc73 protein decorates only the plus ends of Taxol-stabilized microtubules. Thus, the simplest model would be that astral microtubules localize kinesin Khc73 to their plus ends, where Khc73 can interact with cortical Dlg to induce Pins/Dlg/G $\alpha$ cortical polarity over one spindle pole (Fig. 5B). In addition, neuroblasts appear to use a positive feedback loop to maintain microtubule-cortical polarity alignment. Pins directly binds the Mushroom body defective (Mud) protein, a Drosophila NuMA ortholog that binds microtubules and is required for linking Pins to astral microtubules (Bowman et al. 2006; Izumi et al. 2006; Siller et al. 2006). Thus, microtubules can induce Pins cortical polarity, and Pins can interact with Mud to anchor microtubule plus ends (Fig. 5B).

Drosophila neuroblasts are a new system for investigating microtubule-induced cortical polarity, and there are many questions that need to be addressed. (1) How does Khc73 trigger cortical polarity-via transport of Dlg on microtubules, or by "opening" Dlg by disrupting the intramolecular interactions between its SH3-GK domains (McGee et al. 2001)? (2) What provides temporal control, such that Pins/G $\alpha / D$ lg crescents only form at metaphase-is it just the elaboration of the astral microtubule array, or are cell cycle regulators more directly involved? (3) What provides spatial specificity, such that Pins/G $\alpha / D l g$ crescents only form over one spindle polespindle pole asymmetry or rapid positive feedback consolidating the first crescent formed? (4) What is the role of microtubule dynamic instability; can Taxol stabilized microtubules still induce Pins $/ \mathrm{G} \alpha / \mathrm{Dlg}$ cortical polarity? (5) Finally, do other microtubule plus end-associated proteins such as IQGAP1, CLIP-170, EB1, or APC have a role in inducing cortical polarity? It is interesting to note that loss of APC1 or APC2 individually has no detectable effect on NB polarity, but the apc1 apc2 double mutant has a reduction in neuroblast numbers (Akong et al. 2002) similar to pins mutants (Lee et al. 2006). It is not known why apc1 apc2 double mutants have fewer neuroblasts, but it would be interesting to test whether Pins is delocalized in these double mutants, and if so whether this is due to defects in the Khc73 pathway for microtubule-induced cortical polarity.

\section{Microtubules/centrosomes induce cortical polarity in the C. elegans zygote}

In C. elegans, the identity of the first two daughter cells is determined by the asymmetric protein localization during the first cell division. The newly fertilized C. elegans zygote is unpolarized (Goldstein and Hird 1996). The first sign of asymmetry is the loss of cortical contractility (smoothening) over the future posterior pole, while the anterior cortex remains active (ruffling). Within 2 min of posterior pole smoothening, cortical PAR complex proteins (PAR-3, PAR-6, and aPKC) are cleared from the posterior cortex, localizing to the anterior cortex coincident with the anterior movement of myosin II-containing foci. PAR-2, a ring domain protein, is then recruited from the cytoplasm to occupy the "vacant" posterior cortex leading to the production of two nonoverlapping, yet interdependent anterior and posterior cortical domains. These asymmetrically localized 
cortical proteins, and others, are required for positioning the mitotic spindle and polarizing cytoplasmic cell fate determinants resulting in an asymmetric cell division (for review, see Schneider and Bowerman 2003). Altering the sperm entry site changes the position of the posterior cortical domain within the egg, and all later developmental events remain coordinated with the new polarity axis, showing that a sperm-associated structure induces functional cortical polarity (Goldstein and Hird 1996). Anucleate sperm can induce posterior cortical polarity, indicating that the polarizing cue is not the sperm nucleus (Sadler and Shakes 2000). What is the cue? Recent work suggests that microtubules are not involved, but rather the cue comes from the centrosome and/or a sperm provided membraneous organelle. It remains unclear whether either of these structures is sufficient to induce polarity or whether both are required and function in a single or separate pathways.

The centrosome at the one-cell stage in C. elegans likely has dual functions: first, to nucleate microtubules required for spindle formation and equal DNA segregation during cell division, and second, to induce cortical polarity. A role for centrosome-induced cortical polarity independent of microtubules is based on several lines of evidence. First, ablation of the sperm-derived centrosome either genetically ( $s p d-2$ or $s p d-5)$ or by laser irradiation resulted in a delay or absence of posterior cortical smoothening and forming PAR-2 posterior cortical polarity (O'Connell et al. 2000; Hamill et al. 2002; Cowan and Hyman 2004). Second, spd-2(RNAi) centrosomes weakly nucleate microtubules but lack PAR-2 posterior cortical polarity, whereas $\gamma$-tubulin(RNAi) or $\alpha / \beta$-tubulin(RNAi) centrosomes nucleate even fewer microtubules yet have normal PAR-2 posterior cortical polarity (Cowan and Hyman 2004). Finally, cortical polarity forms normally in embryos treated with microtubule depolymerizing drugs (Strome and Wood 1983; Sonneville and Gonczy 2004). Thus, formation of PAR-2 posterior cortical polarity and posterior cortical smoothening is not correlated with the presence or abundance of microtubules, but requires a functional centrosome.

What is the centrosomal component that induces PAR-2 cortical polarity? The first break in symmetry is a localized weakening in the actomyosin contractile network, either due to reduced myosinII activity or fewer microfilaments. This weakening in the network, which lies just below the cell cortex, occurs at a cortical site close to the centrosome and results in a massive rearrangement of the cortical actin network leading to asymmetry in cortical contractility and cytoplasmic flows (Munro et al. 2004). Recent results from several labs suggest that network weakening requires CYK-4, a RhoGAP highly enriched on sperm-associated membranes; weakening also requires the maternally provided RHO and ECT-2 (RhoGEF) proteins (Jenkins et al. 2006; Motegi and Sugimoto 2006; Motegi et al. 2006; Schonegg and Hyman 2006). cyk-4(RNAi), rho(RNAi), and ect-2(RNAi) embryos all fail to establish cortical polarity but for different reasons. Cortical contractility remains uniformly high in cyk-4(RNAi) embryos coincident with uniform high levels of cortical phosphorylated myosin light chain. Conversely, cortical contractility is dramatically reduced in rho(RNAi) and ect-2(RNAi) embryos with no phosphorylated myosin light chain detected at the cortex. These results suggest that CYK-4 may induce weakening in the contractile network by locally inactivating Rho leading to reduced cortical myosin II activity and a localized cortical smoothening that is then propagated toward the anterior. Whether canonical Rho signaling transducers such as Rho kinase are required for myosin II phosphorylation remains unknown. In addition, it is unclear what the relationship is between the centrosome and the CYK-4-containing membrane. Both remain spatially close to one another within the egg, with CYK-4 localizing asymmetrically to the cortex. Is the centrosome required for assembly or function of CYK $-4^{+}$membranes, or does the centrosome provide an independent cue that regulates cortical polarity? The latter model is supported by data from a wide range of systems showing centrosomal regulation of cortical polarity (Piel et al. 2001; de Anda et al. 2005; Gromley et al. 2005; Stinchcombe et al. 2006). In the future, it will be interesting to determine what happens to CYK-4-containing membranes when centrosomes are ablated and vise versa. Perhaps one role for the centrosome is to temporally regulate initiation of cortical polarity, thereby preventing premature polarity establishment prior to completion of meiosis.

While microtubules may not be required for establishing cortical polarity during the one-cell stage, microtubules are required for the asymmetric localization of PAR-2 over the meiotic spindle in the egg, and may be important for the formation of the polar body cortical domain (Wallenfang and Seydoux 2000; Cowan and Hyman 2004). Thus, microtubules induce anterior PAR-2 cortical polarity during polar body formation (Fig. 6, left). The mechanism by which meiotic spindle microtubules
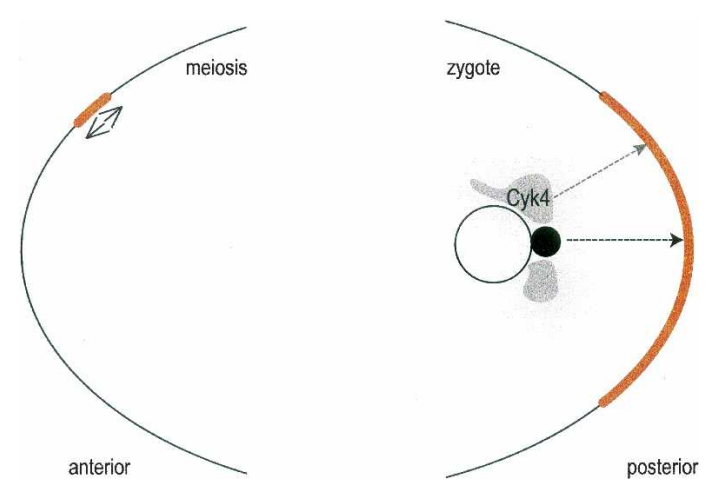

Figure 6. Microtubules/centrosomes induce cortical polarity in the C. elegans zygote. (Left) Microtubules of the meiotic spindle (black lines) induce Par2 cortical polarity at the anterior side of the oocyte. (Right) The mechanisms inducing Par2 cortical polarity at the site of sperm entry could include local inhibition of Rho by the CYK-4 RhoGAP protein localized to the sperm-derived membranes (gray) and/or by an unknown factor present on the sperm-derived centrosome (black). See the text for details. 
promote cortical PAR-2 localization is completely unknown. Based on work in other systems, where the position of the meiotic spindle is correlated with a spot of active CDC42 surrounded by a ring of active Rho at the cortex (Ma et al. 2006), it would be interesting to see if a similar cortical polarity was induced prior to PAR-2 cortical localization, whether microtubules are involved in generating this cortical domain, and whether this cortical domain is required for polar body extrusion.

Despite the new data showing a role for centrosomes and membranes, it may be premature to rule out a role for microtubules. First, microtubules are sufficient to induce PAR-2 cortical polarity during meiosis, and may have a related function after sperm entry. Second, the best evidence against a role for microtubules is that $s p d$ 2(RNAi) embryos nucleate microtubules but fail to induce cortical polarity (Cowan and Hyman 2004), but it is possible that these microtubules are functionally abnormal. If microtubules have a role in stimulating posterior PAR-2 localization, they could act independently or in concert with the centrosome/membrane pathways. For example, even a single microtubule could promote plus end-directed transport of CYK-4(RhoGAP $)^{+}$sperm membranes or the RhoGEF ECT-2 toward the posterior cortex. It is unknown whether the evolutionarily conserved + TIPs-including APC, EB1, and CLIP-170-are required for any aspects of cortical polarity in the one-cell C. elegans embryo; however, the APC ortholog, apr-1, is required at the four-cell stage for the EMS blastomere to generate two distinct cell types, E and MS. While Wnt signaling is required for this cell fate decision, it remains unknown whether APC functions on the microtubule plus end to polarize the cortex. The identification of additional proteins required for cortical polarity will be necessary to distinguish the relative importance of each sperm-derived structure in the induction of zygotic cortical polarity.

\section{Conclusions and future directions}

From these different contexts, one common theme for how microtubules regulate cell polarity is immediately apparent. Microtubules can impart polarity by signaling to the cortex via regulating the localized activation of small G-protein signaling (Table 1). From these systems, it remains unclear how many of the proteins will be conserved in microtubule/cortical polarity pathways and what are and will be the cell type specific differences. It is likely that common components of microtubule-based polarity pathways will include plus end-directed kinesin motor proteins, astral microtubule plus end-stabilizing proteins such as CLIP-170 and EB1, and proteins that function as molecular switches. Once the switch protein (i.e., a GEF or GAP) is delivered to the cortex, conserved (Rho-type GTPase, APC, formin) and unique (PAR-2, Pins/Dlg, PAK) proteins may be activated to respond, interpret, and induce appropriate readouts that are cell type specific. Another shared feature among many cell types is that microtubules and cortical polarity form a positive feedback loop-microtubules induce cortical polarity and then cortical polarity proteins anchor microtubules-that allows microtubules to induce and/or stabilize the axis of cortical polarity in cells lacking a stable extrinsic polarity cue.

Table 1. Microtubule-induced cortical polarity pathway components

\begin{tabular}{|c|c|c|c|c|c|c|}
\hline Cell type & S. pombe & Fibroblast & $\begin{array}{l}\text { Drosophila } \\
\text { neuroblast }\end{array}$ & $\begin{array}{c}\text { Epithelia } \\
\text { (gastrulation) }\end{array}$ & $\begin{array}{l}\text { Epithelia } \\
\text { (cadherin) }\end{array}$ & $\begin{array}{l}\text { C. elegans } \\
\text { oocyte }\end{array}$ \\
\hline $\begin{array}{l}\text { Cortical polarity } \\
\text { output }\end{array}$ & $\begin{array}{l}\text { Polarized cell } \\
\text { growth }\end{array}$ & $\begin{array}{l}\text { Directed cell } \\
\text { migration }\end{array}$ & $\begin{array}{l}\text { Asymmetric cell } \\
\text { division }\end{array}$ & $\begin{array}{l}\text { Apical } \\
\text { constriction }\end{array}$ & Cell-cell adhesion & $\begin{array}{l}\text { Polar-body } \\
\text { extrusion }\end{array}$ \\
\hline $\begin{array}{l}\text { MTs required for } \\
\text { polarity effect }\end{array}$ & No & No & $\mathrm{Yes}^{\mathrm{a}}$ & $?$ & $?$ & Yes \\
\hline $\begin{array}{l}\text { MTs required for } \\
\text { polarity position }\end{array}$ & Yes & Yes & $\mathrm{Yes}^{\mathrm{a}}$ & $?$ & Yes & Yes \\
\hline MT motors & tea2p (kinesin-like) & $?$ & Khc73 & $?$ & $?$ & $\begin{array}{l}\text { Unc-116 (khc1) } \\
\text { Klc1/2 }\end{array}$ \\
\hline MT + TIPS & $\begin{array}{l}\text { tiplp (CLIP-170) } \\
\text { mal3 (EB1-like) }\end{array}$ & $\begin{array}{l}\text { Clip-170 } \\
\text { Clasp } \\
\text { EB-1 } \\
\text { Apc? }\end{array}$ & $\begin{array}{l}\text { Khc73 } \\
\text { Apc? }\end{array}$ & EB-1 & Clip-170 & $?$ \\
\hline $\begin{array}{l}\text { MT cortical polarity } \\
\text { inducers }\end{array}$ & $\begin{array}{l}\text { tealp } \\
\text { tea4p } \\
\text { rgflp (rholGEF)? }\end{array}$ & $\begin{array}{l}\text { Iqgap1 } \\
\text { Trio } \\
\text { Asef } \\
\text { Gef-h1 }\end{array}$ & Khc73 & RhoGEF2? & $?$ & $?$ \\
\hline $\begin{array}{l}\text { Cortical polarity } \\
\text { proteins }\end{array}$ & $\begin{array}{l}\bmod 5 \mathrm{p} \\
\text { for3p (formin) } \\
\text { shk1 (p21 kinase) } \\
\text { rho1? }\end{array}$ & $\begin{array}{l}\text { Rac1 } \\
\text { Iqgap1 } \\
\text { p21 kinase }\end{array}$ & $\begin{array}{l}\text { Dlg } \\
\text { Pins/G } \alpha i\end{array}$ & $\begin{array}{l}\text { Rho1 } \\
\text { MyoII }\end{array}$ & $\begin{array}{l}\text { E-cadherin } \\
\beta \text {-catenin } \\
\text { Rho kinase } \\
\text { MyoII }\end{array}$ & $\begin{array}{l}\text { Rho? } \\
\text { Rho kinase? } \\
\text { MyoII? } \\
\text { Par2 }\end{array}$ \\
\hline $\begin{array}{l}\text { Cortical polarity } \\
\text { MT capture/ } \\
\text { stabilizers }\end{array}$ & $\begin{array}{l}\text { tiplp (CLIP-170) } \\
\text { mal3 (EB1-like) }\end{array}$ & $\begin{array}{l}\text { Clip-170 } \\
\text { Apc } \\
\text { Stathmin }\end{array}$ & $\begin{array}{l}\text { Mud } \\
\text { Dynein }\end{array}$ & Dynein? & Dynein & Dynein? \\
\hline
\end{tabular}

${ }^{\mathrm{a}}$ In absence of Par complex only. 


\section{Acknowledgments}

We thank Rick Horwitz, Vladmir Gelfand, Sophie Martin, Bruce Bowerman, and Karsten Siller for comments on the manuscript. This work was supported by an NIH Developmental Biology Training grant (S.E.S.) and the Howard Hughes Medical Institute, where C.Q.D. is an Investigator.

\section{References}

Affolter, M. and Weijer, C.J. 2005. Signaling to cytoskeletal dynamics during chemotaxis. Dev. Cell 9: 19-34.

Akhmanova, A. and Hoogenraad, C.C. 2005. Microtubule plusend-tracking proteins: Mechanisms and functions. Curr. Opin. Cell Biol. 17: 47-54.

Akong, K., McCartney, B.M., and Peifer, M. 2002. Drosophila APC2 and APC1 have overlapping roles in the larval brain despite their distinct intracellular localizations. Dev. Biol. 250: 71-90.

Andersen, S.S. 2000. Spindle assembly and the art of regulating microtubule dynamics by MAPs and Stathmin/Op18. Trends Cell Biol. 10: 261-267.

Asaba, N., Hanada, T., Takeuchi, A., and Chishti, A.H. 2003. Direct interaction with a kinesin-related motor mediates transport of mammalian discs large tumor suppressor homologue in epithelial cells. J. Biol. Chem. 278: 8395-8400.

Banerjee, M., Worth, D., Prowse, D.M., and Nikolic, M. 2002. Pak1 phosphorylation on 212 affects microtubules in cells undergoing mitosis. Curr. Biol. 12: 1233-1239.

Barrett, K., Leptin, M., and Settleman, J. 1997. The Rho GTPase and a putative RhoGEF mediate a signaling pathway for the cell shape changes in Drosophila gastrulation. Cell 91: 905915.

Behrens, R. and Nurse, P. 2002. Roles of fission yeast tealp in the localization of polarity factors and in organizing the microtubular cytoskeleton. J. Cell Biol. 157: 783-793.

Bement, W.M., Benink, H.A., and von Dassow, G. 2005. A microtubule-dependent zone of active RhoA during cleavage plane specification. J. Cell Biol. 170: 91-101.

Benais-Pont, G., Punn, A., Flores-Maldonado, C., Eckert, J., Raposo, G., Fleming, T.P., Cereijido, M., Balda, M.S., and Matter, K. 2003. Identification of a tight junction-associated guanine nucleotide exchange factor that activates Rho and regulates paracellular permeability. J. Cell Biol. 160: 729740.

Bershadsky, A.D., Vaisberg, E.A., and Vasiliev, J.M. 1991. Pseudopodial activity at the active edge of migrating fibroblast is decreased after drug-induced microtubule depolymerization. Cell Motil. Cytoskeleton 19: 152-158.

Bilder, D. 2004. Epithelial polarity and proliferation control: Links from the Drosophila neoplastic tumor suppressors. Genes \& Dev. 18: 1909-1925.

Blangy, A., Vignal, E., Schmidt, S., Debant, A., Gauthier-Rouviere, C., and Fort, P. 2000. TrioGEF1 controls Rac- and Cdc42-dependent cell structures through the direct activation of rhoG. J. Cell Sci. 113: 729-739.

Bowman, S.K., Neumuller, R.A., Novatchkova, M., Du, Q., and Knoblich, J.A. 2006. The Drosophila NuMA Homolog Mud regulates spindle orientation in asymmetric cell division. Dev. Cell 10: 731-742.

Braga, V.M., Machesky, L.M., Hall, A., and Hotchin, N.A. 1997. The small GTPases Rho and Rac are required for the establishment of cadherin-dependent cell-cell contacts. J. Cell Biol. 137: 1421-1431.

Bretscher, A. 2005. Microtubule tips redirect actin assembly. Dev. Cell 8: 458-459.
Briggs, M.W. and Sacks, D.B. 2003. IQGAP proteins are integral components of cytoskeletal regulation. EMBO Rep. 4: 571574.

Broadus, J. and Doe, C.Q. 1997. Extrinsic cues, intrinsic cues and microfilaments regulate asymmetric protein localization in Drosophila neuroblasts. Curr. Biol. 7: 827-835.

Browning, H., Hackney, D.D., and Nurse, P. 2003. Targeted movement of cell end factors in fission yeast. Nat. Cell Biol. 5: 812-818.

Buck, K.B. and Zheng, J.Q. 2002. Growth cone turning induced by direct local modification of microtubule dynamics. $I$. Neurosci. 22: 9358-9367.

Busch, K.E., Hayles, J., Nurse, P., and Brunner, D. 2004. Tea2p kinesin is involved in spatial microtubule organization by transporting tiplp on microtubules. Dev. Cell 6: 831-843.

Callow, M.G., Zozulya, S., Gishizky, M.L., Jallal, B., and Smeal, T. 2005. PAK4 mediates morphological changes through the regulation of GEF-H1. J. Cell Sci. 118: 1861-1872.

Carvalho, P., Tirnauer, J.S., and Pellman, D. 2003. Surfing on microtubule ends. Trends Cell Biol. 13: 229-237.

Cowan, C.R. and Hyman, A.A. 2004. Centrosomes direct cell polarity independently of microtubule assembly in C. elegans embryos. Nature 431: 92-96.

D'Avino, P.P., Savoian, M.S., and Glover, D.M. 2005. Cleavage furrow formation and ingression during animal cytokinesis: A microtubule legacy. J. Cell Sci. 118: 1549-1558.

Daub, H., Gevaert, K., Vandekerckhove, J., Sobel, A., and Hall, A. 2001. Rac/Cdc42 and p65PAK regulate the microtubuledestabilizing protein stathmin through phosphorylation at serine 16. J. Biol. Chem. 276: 1677-1680.

de Anda, F.C., Pollarolo, G., Da Silva, J.S., Camoletto, P.G., Feiguin, F., and Dotti, C.G. 2005. Centrosome localization determines neuronal polarity. Nature 436: 704-708.

Drummond, D.R. and Cross, R.A. 2000. Dynamics of interphase microtubules in Schizosaccharomyces pombe. Curr. Biol. 10: $766-775$.

Etienne-Manneville, S. 2006. In vitro assay of primary astrocyte migration as a tool to study Rho GTPase function in cell polarization. Methods Enzymol. 406: 565-578.

Etienne-Manneville, S. and Hall, A. 2003. Cde42 regulates GSK$3 \beta$ and adenomatous polyposis coli to control cell polarity. Nature 421: 753-756.

Ezratty, E.J., Partridge, M.A., and Gundersen, G.G. 2005. Microtubule-induced focal adhesion disassembly is mediated by dynamin and focal adhesion kinase. Nat. Cell Biol. 7: 581590.

Feierbach, B. and Chang, F. 2001. Roles of the fission yeast formin for3p in cell polarity, actin cable formation and symmetric cell division. Curr. Biol. 11: 1656-1665.

Feierbach, B., Verde, F., and Chang, F. 2004. Regulation of a formin complex by the microtubule plus end protein tealp. J. Cell Biol. 165: 697-707.

Fukata, M., Watanabe, T., Noritake, J., Nakagawa, M., Yamaga, M., Kuroda, S., Matsuura, Y., Iwamatsu, A., Perez, F., and Kaibuchi, K. 2002. Rac1 and Cdc42 capture microtubules through IQGAP1 and CLIP-170. Cell 109: 873-885.

Galjart, N. and Perez, F. 2003. A plus-end raft to control microtubule dynamics and function. Curr. Opin. Cell Biol. 15: 48-53.

Gao, Y., Xing, J., Streuli, M., Leto, T.L., and Zheng, Y. 2001. $\operatorname{Trp}(56)$ of rac1 specifies interaction with a subset of guanine nucleotide exchange factors. I. Biol. Chem. 276: 4753047541.

Garcia, P., Tajadura, V., Garcia, I., and Sanchez, Y. 2006a. Rgflp is a specific Rho1-GEF that coordinates cell polarization with cell wall biogenesis in fission yeast. Mol. Biol. Cell 17: 
$1620-1631$.

Garcia, P., Tajadura, V., Garcia, I., and Sanchez, Y. 2006b. Role of Rho GTPases and Rho-GEFs in the regulation of cell shape and integrity in fission yeast. Yeast 23: 1031-1043.

Glaven, J.A., Whitehead, I., Bagrodia, S., Kay, R., and Cerione, R.A. 1999. The Dbl-related protein, Lfc, localizes to microtubules and mediates the activation of Rac signaling pathways in cells. J. Biol. Chem. 274: 2279-2285.

Glynn, J.M., Lustig, R.J., Berlin, A., and Chang, F. 2001. Role of bud6p and tealp in the interaction between actin and microtubules for the establishment of cell polarity in fission yeast. Curr. Biol. 11: 836-845.

Goldman, R.D. 1971. The role of three cytoplasmic fibers in BHK-21 cell motility. I. Microtubules and the effects of colchicine. J. Cell Biol. 51: 752-762.

Goldstein, B. and Hird, S.N. 1996. Specification of the anteroposterior axis in Caenorhabditis elegans. Development 122: $1467-1474$

Grigoriev, I.S., Chernobelskaya, A.A., and Vorobjev, I.A. 1999. Nocodazole, vinblastine and taxol at low concentrations affect fibroblast locomotion and saltatory movements of organelles. Membr. Cell Biol. 13: 23-48.

Gromley, A., Yeaman, C., Rosa, J., Redick, S., Chen, C.T., Mirabelle, S., Guha, M., Sillibourne, J., and Doxsey, S.J. 2005. Centriolin anchoring of exocyst and SNARE complexes at the midbody is required for secretory-vesicle-mediated abscission. Cell 123: 75-87.

Gundersen, G.G., Wen, Y., Eng, C.H., Schmoranzer, J., CabreraPoch, N., Morris, E.J., Chen, M., and Gomes, E.R. 2005. Regulation of microtubules by Rho GTPases in migrating cells. Novartis Found. Symp. 269: 106-116; discussion 116126, 223-130.

Hacker, U. and Perrimon, N. 1998. DRhoGEF2 encodes a member of the Dbl family of oncogenes and controls cell shape changes during gastrulation in Drosophila. Genes \& Dev. 12: 274-284.

Hall, A. 2005. Rho GTPases and the control of cell behaviour. Biochem. Soc. Trans. 33: 891-895.

Hamill, D.R., Severson, A.F., Carter, J.C., and Bowerman, B. 2002. Centrosome maturation and mitotic spindle assembly in C. elegans require SPD-5, a protein with multiple coiledcoil domains. Dev. Cell 3: 673-684.

Hanada, T., Lin, L., Tibaldi, E.V., Reinherz, E.L., and Chishti, A.H. 2000. GAKIN, a novel kinesin-like protein associates with the human homologue of the Drosophila discs large tumor suppressor in T lymphocytes. I. Biol. Chem. 275: 28774-28784.

Honigberg, L. and Kenyon, C. 2000. Establishment of left/right asymmetry in neuroblast migration by UNC-40/DCC, UNC-73/Trio and DPY-19 proteins in C. elegans. Development 127: 4655-4668.

Izumi, Y., Ohta, N., Hisata, K., Raabe, T., and Matsuzaki, F. 2006. Drosophila Pins-binding protein Mud regulates spindle-polarity coupling and centrosome organization. Nat. Cell Biol. 8: 586-593.

Jankovics, F. and Brunner, D. 2006. Transiently reorganized microtubules are essential for zippering during dorsal closure in Drosophila melanogaster. Dev. Cell 11: 375-385.

Jenkins, N., Saam, J.R., and Mango, S.E. 2006. CYK-4/GAP provides a localized cue to initiate anteroposterior polarity upon fertilization. Science 313: 1298-1301.

Kabir, N., Schaefer, A.W., Nakhost, A., Sossin, W.S., and Forscher, P. 2001. Protein kinase C activation promotes microtubule advance in neuronal growth cones by increasing average microtubule growth lifetimes. J. Cell Biol. 152: 10331044.
Kaverina, I., Krylyshkina, O., and Small, J.V. 1999. Microtubule targeting of substrate contacts promotes their relaxation and dissociation. J. Cell Biol. 146: 1033-1044.

Kawasaki, Y., Senda, T., Ishidate, T., Koyama, R., Morishita, T., Iwayama, Y., Higuchi, O., and Akiyama, T. 2000. Asef, a link between the tumor suppressor APC and G-protein signaling. Science 289: 1194-1197.

Kawasaki, Y., Sato, R., and Akiyama, T. 2003. Mutated APC and Asef are involved in the migration of colorectal tumour cells. Nat. Cell Biol. 5: 211-215.

Knoblich, J.A., Jan, L.Y., and Jan, Y.N. 1995. Asymmetric segregation of Numb and Prospero during cell division. Nature 377: 624-627.

Krendel, M., Zenke, F.T., and Bokoch, G.M. 2002. Nucleotide exchange factor GEF-H1 mediates cross-talk between microtubules and the actin cytoskeleton. Nat. Cell Biol. 4: 294301.

Lee, H., Engel, U., Rusch, J., Scherrer, S., Sheard, K., and Van Vactor, D. 2004. The microtubule plus end tracking protein Orbit/MAST/CLASP acts downstream of the tyrosine kinase Abl in mediating axon guidance. Neuron 42: 913-926.

Lee, C.Y., Robinson, K.J., and Doe, C.Q. 2006. Lgl, Pins and aPKC regulate neuroblast self-renewal versus differentiation. Nature 439: 594-598.

Li, H.P., Liu, Z.M., and Nirenberg, M. 1997. Kinesin-73 in the nervous system of Drosophila embryos. Proc. Natl. Acad. Sci. 94: 1086-1091.

Liao, G., Nagasaki, T., and Gundersen, G.G. 1995. Low concentrations of nocodazole interfere with fibroblast locomotion without significantly affecting microtubule level: Implications for the role of dynamic microtubules in cell locomotion. J. Cell Sci. 108: 3473-3483.

Ma, C., Benink, H.A., Cheng, D., Montplaisir, V., Wang, L., Xi, Y., Zheng, P.P., Bement, W.M., and Liu, X.J. 2006. Cde42 activation couples spindle positioning to first polar body formation in oocyte maturation. Curr. Biol. 16: 214-220.

Marks, J., Hagan, I.M., and Hyams, J.S. 1986. Growth polarity and cytokinesis in fission yeast: The role of the cytoskeleton. J. Cell Sci. Suppl. 5: 229-241.

Martin, S.G., McDonald, W.H., Yates III, J.R., and Chang, F. 2005. Tea4p links microtubule plus ends with the formin for3p in the establishment of cell polarity. Dev. Cell 8: 479491.

Mary, S., Charrasse, S., Meriane, M., Comunale, F., Travo, P., Blangy, A., and Gauthier-Rouviere, C. 2002. Biogenesis of $\mathrm{N}$-cadherin-dependent cell-cell contacts in living fibroblasts is a microtubule-dependent kinesin-driven mechanism. Mol. Biol. Cell 13: 285-301.

Mataraza, J.M., Briggs, M.W., Li, Z., Entwistle, A., Ridley, A.J., and Sacks, D.B. 2003. IQGAP1 promotes cell motility and invasion. J. Biol. Chem. 278: 41237-41245.

McGee, A.W., Dakoji, S.R., Olsen, O., Bredt, D.S., Lim, W.A., and Prehoda, K.E. 2001. Structure of the SH3-guanylate kinase module from PSD-95 suggests a mechanism for regulated assembly of MAGUK scaffolding proteins. Mol. Cell 8: 1291-1301.

Mikhailov, A. and Gundersen, G.G. 1998. Relationship between microtubule dynamics and lamellipodium formation revealed by direct imaging of microtubules in cells treated with nocodazole or taxol. Cell Motil. Cytoskeleton 41: 325340.

Mitchison, J.M. and Nurse, P. 1985. Growth in cell length in the fission yeast Schizosaccharomyces pombe. J. Cell Sci. 75: 357-376.

Motegi, F. and Sugimoto, A. 2006. Sequential functioning of the ECT-2 RhoGEF, RHO-1 and CDC-42 establishes cell polar- 
ity in Caenorhabditis elegans embryos. Nat. Cell Biol. 8: 978-985.

Motegi, F., Velarde, N.V., Piano, F., and Sugimoto, A. 2006. Two phases of astral microtubule activity during cytokinesis in C. elegans embryos. Dev. Cell 10: 509-520.

Munro, E., Nance, J., and Priess, J.R. 2004. Cortical flows powered by asymmetrical contraction transport PAR proteins to establish and maintain anterior-posterior polarity in the early C. elegans embryo. Dev. Cell 7: 413-424.

Nikolaidou, K.K. and Barrett, K. 2004. A Rho GTPase signaling pathway is used reiteratively in epithelial folding and potentially selects the outcome of Rho activation. Curr. Biol. 14: 1822-1826.

O'Connell, K.F., Maxwell, K.N., and White, J.G. 2000. The spd-2 gene is required for polarization of the anteroposterior axis and formation of the sperm asters in the Caenorhabditis elegans zygote. Dev. Biol. 222: 55-70.

Padash Barmchi, M., Rogers, S., and Hacker, U. 2005. DRhoGEF2 regulates actin organization and contractility in the Drosophila blastoderm embryo. J. Cell Biol. 168: 575-585.

Piel, M., Nordberg, J., Euteneuer, U., and Bornens, M. 2001. Centrosome-dependent exit of cytokinesis in animal cells. Science 291: 1550-1553.

Ren, Y., Li, R., Zheng, Y., and Busch, H. 1998. Cloning and characterization of GEF-H1, a microtubule-associated guanine nucleotide exchange factor for Rac and Rho GTPases. J. Biol. Chem. 273: 34954-34960.

Ridley, A.J., Paterson, H.F., Johnston, C.L., Diekmann, D., and Hall, A. 1992. The small GTP-binding protein rac regulates growth factor-induced membrane ruffling. Cell 70: 401-410.

Rodriguez, O.C., Schaefer, A.W., Mandato, C.A., Forscher, P., Bement, W.M., and Waterman-Storer, C.M. 2003. Conserved microtubule-actin interactions in cell movement and morphogenesis. Nat. Cell Biol. 5: 599-609.

Rogers, S.L., Wiedemann, U., Hacker, U., Turck, C., and Vale, R.D. 2004. Drosophila RhoGEF2 associates with microtubule plus ends in an EB1-dependent manner. Curr. Biol. 14: 1827-1833.

Rossman, K.L., Der, C.J., and Sondek, J. 2005. GEF means go: Turning on RHO GTPases with guanine nucleotide-exchange factors. Nat. Rev. Mol. Cell Biol. 6: 167-180.

Rupes, I., Jia, Z., and Young, P.G. 1999. Ssp1 promotes actin depolymerization and is involved in stress response and new end take-off control in fission yeast. Mol. Biol. Cell 10: 14951510.

Sadler, P.L. and Shakes, D.C. 2000. Anucleate Caenorhabditis elegans sperm can crawl, fertilize oocytes and direct anterior-posterior polarization of the 1-cell embryo. Development 127: 355-366.

Sawin, K.E. and Snaith, H.A. 2004. Role of microtubules and tealp in establishment and maintenance of fission yeast cell polarity. J. Cell Sci. 117: 689-700.

Schaefer, A.W., Kabir, N., and Forscher, P. 2002. Filopodia and actin arcs guide the assembly and transport of two populations of microtubules with unique dynamic parameters in neuronal growth cones. J. Cell Biol. 158: 139-152.

Schneider, S.Q. and Bowerman, B. 2003. Cell polarity and the cytoskeleton in the Caenorhabditis elegans zygote. Annu. Rev. Genet. 37: 221-249.

Schonegg, S. and Hyman, A.A. 2006. CDC-42 and RHO-1 coordinate acto-myosin contractility and PAR protein localization during polarity establishment in C. elegans embryos. Development 133: 3507-3516.

Shewan, A.M., Maddugoda, M., Kraemer, A., Stehbens, S.J., Verma, S., Kovacs, E.M., and Yap, A.S. 2005. Myosin 2 is a key Rho kinase target necessary for the local concentration of E-cadherin at cell-cell contacts. Mol. Biol. Cell 16: 45314542 .

Shimada, Y., Yonemura, S., Ohkura, H., Strutt, D., and Uemura, T. 2006. Polarized transport of Frizzled along the planar microtubule arrays in Drosophila wing epithelium. Dev. Cell 10: 209-222.

Shimomura, A., Kohu, K., Akiyama, T., and Senda, T. 2005. Subcellular localization of the tumor suppressor protein APC in developing cultured neurons. Neurosci. Lett. 375: $81-86$.

Shpetner, H.S. and Vallee, R.B. 1992. Dynamin is a GTPase stimulated to high levels of activity by microtubules. Nature 355: 733-735.

Sieberer, B.J., Ketelaar, T., Esseling, J.J., and Emons, A.M. 2005. Microtubules guide root hair tip growth. New Phytol. 167: 711-719.

Siegrist, S.E. and Doe, C.Q. 2005. Microtubule-induced Pins/ Gai cortical polarity in Drosophila neuroblasts. Cell 123: 1323-1335.

Siller, K.H., Cabernard, C., and Doe, C.Q. 2006. The NuMArelated Mud protein binds Pins and regulates spindle orientation in Drosophila neuroblasts. Nat. Cell Biol. 8: 594-600.

Small, J.V. and Kaverina, I. 2003. Microtubules meet substrate adhesions to arrange cell polarity. Curr. Opin. Cell Biol. 15: 40-47.

Snaith, H.A. and Sawin, K.E. 2003. Fission yeast mod5p regulates polarized growth through anchoring of tealp at cell tips. Nature 423: 647-651.

Snaith, H.A., Samejima, I., and Sawin, K.E. 2005. Multistep and multimode cortical anchoring of tealp at cell tips in fission yeast. EMBO T. 24: 3690-3699.

Sonneville, R. and Gonczy, P. 2004. Zyg-11 and cul-2 regulate progression through meiosis II and polarity establishment in C. elegans. Development 131: 3527-3543.

Spana, E.P. and Doe, C.Q. 1995. The prospero transcription factor is asymmetrically localized to the cell cortex during neuroblast mitosis in Drosophila. Development 121: 31873195.

Stehbens, S.J., Paterson, A.D., Crampton, M.S., Shewan, A.M., Ferguson, C., Akhmanova, A., Parton, R.G., and Yap, A.S. 2006. Dynamic microtubules regulate the local concentration of E-cadherin at cell-cell contacts. J. Cell Sci. 119: 18011811.

Stepanova, T., Slemmer, J., Hoogenraad, C.C., Lansbergen, G., Dortland, B., De Zeeuw, C.I., Grosveld, F., van Cappellen, G., Akhmanova, A., and Galjart, N. 2003. Visualization of microtubule growth in cultured neurons via the use of EB3GFP (end-binding protein 3-green fluorescent protein). J. Neurosci. 23: 2655-2664.

Stinchcombe, J.C., Majorovits, E., Bossi, G., Fuller, S., and Griffiths, G.M. 2006. Centrosome polarization delivers secretory granules to the immunological synapse. Nature 443: 462465.

Strome, S. and Wood, W.B. 1983. Generation of asymmetry and segregation of germ-line granules in early C. elegans embryos. Cell 35: 15-25.

Suter, D.M. and Forscher, P. 1998. An emerging link between cytoskeletal dynamics and cell adhesion molecules in growth cone guidance. Curr. Opin. Neurobiol. 8: 106-116.

Takaishi, K., Sasaki, T., Kotani, H., Nishioka, H., and Takai, Y. 1997. Regulation of cell-cell adhesion by rac and rho small G proteins in MDCK cells. J. Cell Biol. 139: 1047-1059.

Takeichi, M. 1991. Cadherin cell adhesion receptors as a morphogenetic regulator. Science 251: 1451-1455.

Tatebe, H., Shimada, K., Uzawa, S., Morigasaki, S., and Shiozaki, K. 2005. Wsh3/Tea4 is a novel cell-end factor es- 
sential for bipolar distribution of Teal and protects cell polarity under environmental stress in S. pombe. Curr. Biol. 15: 1006-1015.

Umesono, K., Toda, T., Hayashi, S., and Yanagida, M. 1983. Cell division cycle genes nda2 and nda3 of the fission yeast Schizosaccharomyces pombe control microtubular organization and sensitivity to anti-mitotic benzimidazole compounds. J. Mol. Biol. 168: 271-284.

Vaezi, A., Bauer, C., Vasioukhin, V., and Fuchs, E. 2002. Actin cable dynamics and Rho/Rock orchestrate a polarized cytoskeletal architecture in the early steps of assembling a stratified epithelium. Dev. Cell 3: 367-381.

Vasiliev, J.M., Gelfand, I.M., Domnina, L.V., Ivanova, O.Y., Komm, S.G., and Olshevskaja, L.V. 1970. Effect of colcemid on the locomotory behaviour of fibroblasts. J. Embryol. Exp. Morphol. 24: 625-640.

Vaughan, K.T. 2004. Surfing, regulating and capturing: Are all microtubule-tip-tracking proteins created equal? Trends Cell Biol. 14: 491-496.

Wallenfang, M.R. and Seydoux, G. 2000. Polarization of the anterior-posterior axis of C. elegans is a microtubule-directed process. Nature 408: 89-92.

Watanabe, T., Wang, S., Noritake, J., Sato, K., Fukata, M., Takefuji, M., Nakagawa, M., Izumi, N., Akiyama, T., and Kaibuchi, K. 2004. Interaction with IQGAP1 links APC to Rac1, Cdc42, and actin filaments during cell polarization and migration. Dev. Cell 7: 871-883.

Watanabe, T., Noritake, J., and Kaibuchi, K. 2005. Regulation of microtubules in cell migration. Trends Cell Biol. 15: 76-83.

Waterman-Storer, C.M., Worthylake, R.A., Liu, B.P., Burridge, K., and Salmon, E.D. 1999. Microtubule growth activates Rac1 to promote lamellipodial protrusion in fibroblasts. Nat. Cell Biol. 1: 45-50.

Waterman-Storer, C.M., Salmon, W.C., and Salmon, E.D. 2000. Feedback interactions between cell-cell adherens junctions and cytoskeletal dynamics in newt lung epithelial cells. Mol. Biol. Cell 11: 2471-2483.

Williamson, T., Gordon-Weeks, P.R., Schachner, M., and Taylor, J. 1996. Microtubule reorganization is obligatory for growth cone turning. Proc. Nat1. Acad. Sci. 93: 1522115226.

Wittmann, T. and Waterman-Storer, C.M. 2001. Cell motility: Can Rho GTPases and microtubules point the way? J. Cell Sci. 114: 3795-3803.

Wittmann, T., Bokoch, G.M., and Waterman-Storer, C.M. 2004. Regulation of microtubule destabilizing activity of Op18/ stathmin downstream of Rac1. J. Biol. Chem. 279: 61966203.

Wu, X., Xiang, X., and Hammer III, J.A. 2006. Motor proteins at the microtubule plus-end. Trends Cell Biol. 16: 135-143.

Zenke, F.T., Krendel, M., DerMardirossian, C., King, C.C., Bohl, B.P., and Bokoch, G.M. 2004. p21-activated kinase 1 phosphorylates and regulates $14-3-3$ binding to GEF-H1, a microtubule-localized Rho exchange factor. J. Biol. Chem. 279: 18392-18400.

Zhou, F.Q., Waterman-Storer, C.M., and Cohan, C.S. 2002. Focal loss of actin bundles causes microtubule redistribution and growth cone turning. J. Cell Biol. 157: 839-849.

Zhou, F.Q., Zhou, J., Dedhar, S., Wu, Y.H., and Snider, W.D. 2004. NGF-induced axon growth is mediated by localized inactivation of GSK-3 $\beta$ and functions of the microtubule plus end binding protein APC. Neuron 42: 897-912.

Zumbrunn, J., Kinoshita, K., Hyman, A.A., and Nathke, I.S. 2001. Binding of the adenomatous polyposis coli protein to microtubules increases microtubule stability and is regulated by GSK3 $\beta$ phosphorylation. Curr. Biol. 11: 44-49. 


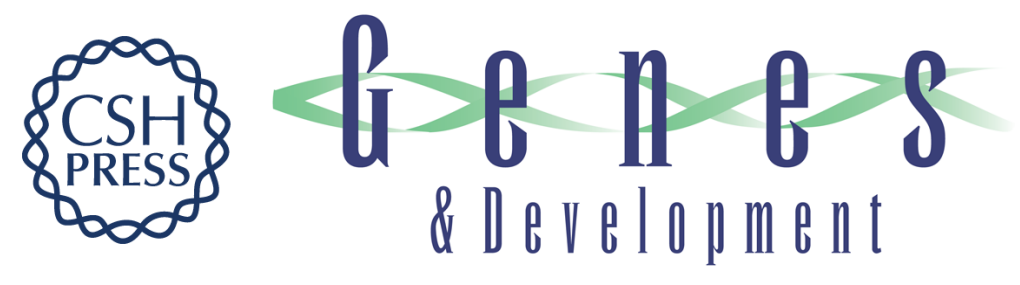

\title{
Microtubule-induced cortical cell polarity
}

\author{
Sarah E. Siegrist and Chris Q. Doe
}

Genes Dev. 2007, 21:

Access the most recent version at doi:10.1101/gad.1511207

References This article cites 126 articles, 52 of which can be accessed free at: http://genesdev.cshlp.org/content/21/5/483.full.html\#ref-list-1

License Freely available online through the Genes \& Development Open Access option.

Email Alerting Receive free email alerts when new articles cite this article - sign up in the box at the top Service right corner of the article or click here.

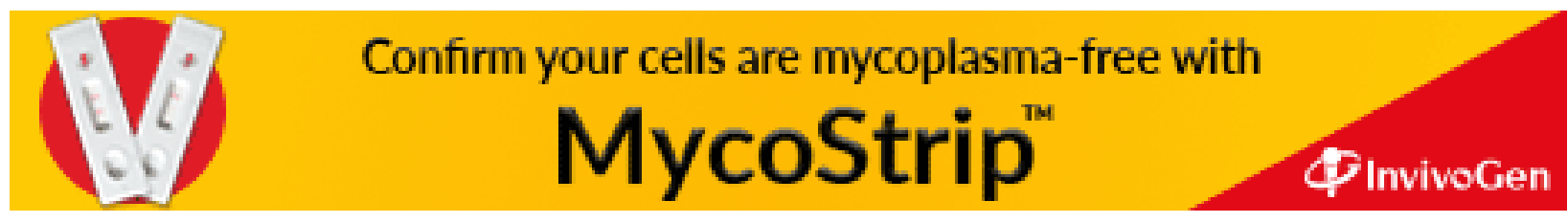

